
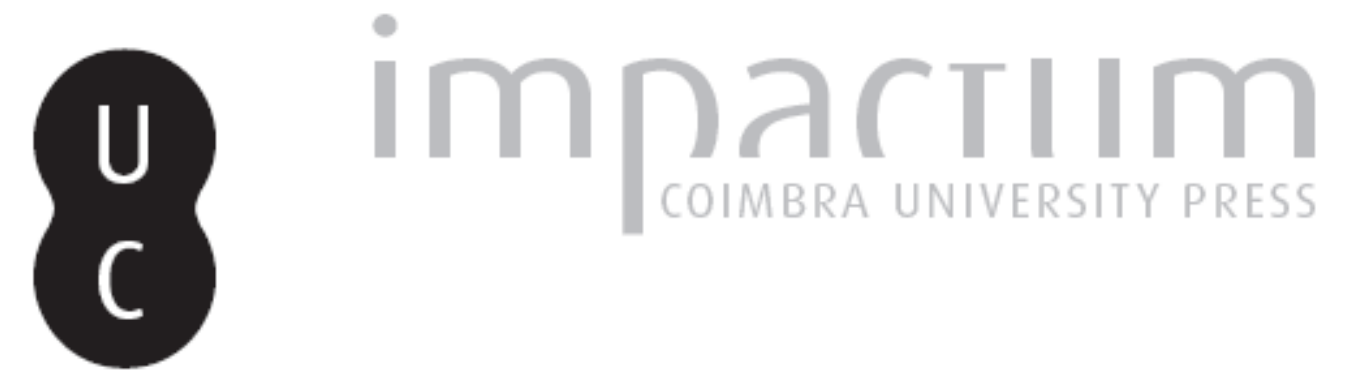

\title{
As legitimações do reinado de $D$. Dinis
}

Autor(es): $\quad$ Ventura, Leontina; Matos, João da Cunha

Publicado por: Faculdade de Letras da Universidade de Coimbra, Instituto de História Económica e Social

URL persistente:

URI:http://hdl.handle.net/10316.2/33472

DOI:

DOI:http://dx.doi.org/10.14195/0870-4147_44_10

Accessed : $\quad$ 26-Apr-2023 15:38:56

A navegação consulta e descarregamento dos títulos inseridos nas Bibliotecas Digitais UC Digitalis, UC Pombalina e UC Impactum, pressupõem a aceitação plena e sem reservas dos Termos e Condições de Uso destas Bibliotecas Digitais, disponíveis em https://digitalis.uc.pt/pt-pt/termos.

Conforme exposto nos referidos Termos e Condições de Uso, o descarregamento de títulos de acesso restrito requer uma licença válida de autorização devendo o utilizador aceder ao(s) documento(s) a partir de um endereço de IP da instituição detentora da supramencionada licença.

Ao utilizador é apenas permitido o descarregamento para uso pessoal, pelo que o emprego do(s) título(s) descarregado(s) para outro fim, designadamente comercial, carece de autorização do respetivo autor ou editor da obra.

Na medida em que todas as obras da UC Digitalis se encontram protegidas pelo Código do Direito de Autor e Direitos Conexos e demais legislação aplicável, toda a cópia, parcial ou total, deste documento, nos casos em que é legalmente admitida, deverá conter ou fazer-se acompanhar por este aviso. 


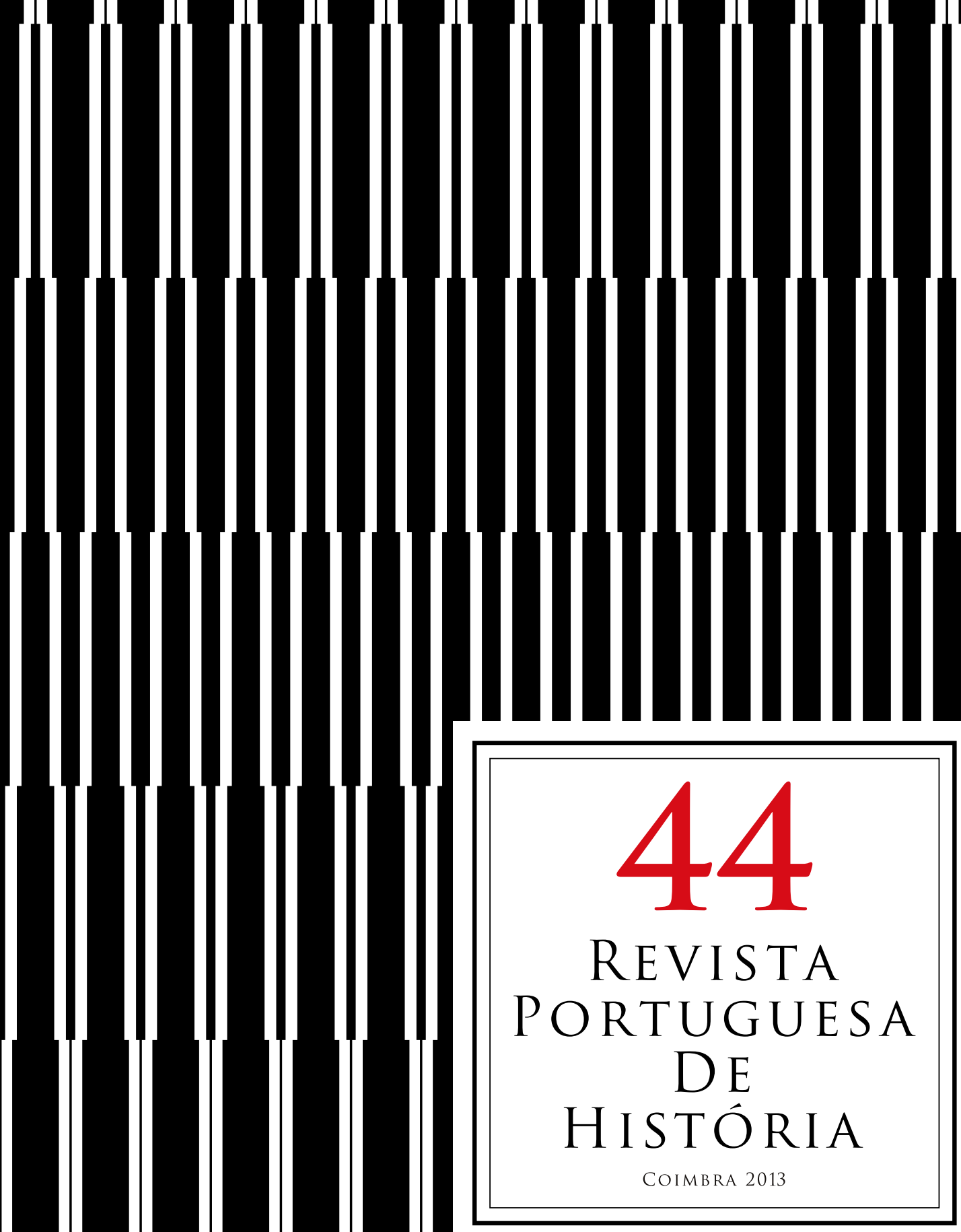




\title{
As Legitimações do Reinado de D. Dinis
}

\author{
LEONTINA VENTURA \\ Professora da Universidade de Coimbra \\ Investigadora do Centro de História da Sociedade e da Cultura \\ ldvdf@fl.uc.pt \\ Joño da Cunha Matos \\ Professor Coordenador aposentado do Instituto Politécnico de Tomar. \\ jcunhamatos@hotmail.com
}

\section{Resumo:}

Com base na legislação, em doações feitas a barregãs do rei e em todas as cartas de legitimação existentes nas Chancelarias de D. Afonso III e na de seu filho, o rei D. Dinis, ele próprio nascido em situação de ilegitimidade, estuda-se a gestação e o tímido início do processo de legitimação em Portugal ao tempo do primeiro daqueles monarcas, bem como o seu posterior desenvolvimento no reinado de seu filho, durante o qual são expedidas duas centenas de cartas de legitimação cujas características são detalhadamente enunciadas.

Palavras chave:

Rei D. Afonso III; Rei D. Dinis; Legitimações; Barregãs do Rei; Nobreza; Clero.

\section{Abstract:}

Based in the legislation, on donations to the king's barregãs (concubines) and in all the letters of legitimation existing in the Chanceries of D. Afonso III and of his son, King Dinis, himself an illegitimate son when he was born, a study is presented of the inception and the timid beginnings of the legitimation process in Portugal at the time of the former monarch. The study proceeds to analyse the legitimation process in the reign of D. Dinis, a period when two hundred letters of legitimation were issued, the characteristics of which are described in detail.

Keywords:

King Afonso III; King Dinis; Legitimations; King's barregãs (concubines); Nobility; Clergy. 
Nascido em 9 de Outubro de 1261, quando o casamento de D. Afonso III com D. Beatriz, filha bastarda do Rei D. Afonso X de Castela, ainda não fora legitimado, D. Dinis, à luz da lei, foi gerado bastardo. Filho, portanto, de uma bastarda e, ele próprio, um bastardo também. Só cerca de meio ano depois do seu nascimento, em Maio de 1262, os bispos portugueses solicitam ao Papa que legitime aquele casamento, tendo em vista a sua prole e, em especial, a sucessão do Reino' ${ }^{1}$. A legitimidade de D. Dinis, o varão primogénito, destinado a reinar, dependeu de uma decisão papal. A sua fugaz situação de bastardia teria sido bastante, segundo alguns, para provocar acesas guerras com o irmão secundogénito D. Afonso ${ }^{2}$. Amou, depois, sobretudo, os seus próprios filhos bastardos, o que provocou novas guerras com o seu filho herdeiro. E no fim de uma extensa vida, abandonado pelas grandes famílias da nobreza, é naqueles seus filhos bastardos que encontra os únicos sustentáculos da sua coroa ${ }^{3}$.

\section{Objectivo do estudo}

D. Dinis, no decurso do seu longo reinado, concedeu um assinalável número de cartas de legitimação - objecto do nosso estudo ${ }^{4}$ - por intermédio das quais

1 (...) Ut ad successionem Regni post mortem patris, et ad quislibet alios actus deinceps legitimi habeantur (Carta dos prelados do Reino solicitando ao Papa o levantamento do interdito e a dispensa de consanguinidade entre o Rei e sua mulher D. Beatriz, datada de Braga, de Maio de 1262, in Chancelaria de D. Afonso III, ed. de Leontina Ventura e António Resende de Oliveira, Coimbra: Imprensa da Universidade de Coimbra, 2006, Livro I. Vol. 2, doc. 690).

2 No que toca ao nascimento, legítimo ou não, do infante D. Afonso apenas nos podemos apoiar em duas datas. A primeira consiste no pedido que os bispos fizeram ao Papa para que o casamento régio fosse considerado como válido ou legítimo. O documento existe e, como já se disse, tem a data de Maio de 1262 (cf. nota anterior). A segunda baseia-se na data do nascimento do Infante, ocorrido a 6 de Fevereiro de 1263 (Livro das Eras de Santa Cruz, fl. 12). Para além de sublinharmos a coincidência de a mediação entre a data do pedido e a do nascimento do Infante ser de nove meses, parece-nos bastante aceitável que, quando ele nasceu, já decorrera tempo mais do que suficiente para a resposta poder ter chegado ao Reino. Porém, muito embora Fr. Francisco Brandão acreditasse que a resposta pontifícia - documento que nunca encontrara - veio no mesmo ano em que o pedido foi formulado (Monarquia Lusitana, V, fls. 36v-38v), a publicação por I. Rodriguez Lama da bula Qui celestia, de 19 de Junho de 1263, onde o Papa Urbano IV permitia a continuação da conjugalis copula parece provar a ilegitimidade do infante Afonso (cfr. José Mattoso, "O triunfo da monarquia portuguesa: 1250-1264. Ensaio de história política”, Análise Social, vol. XXXV (157), 2001, p.919; J.A. de Sotto Mayor Pizarro, D. Dinis, Lisboa: Círculo de Leitores, p. 48 e 265).

3 J.A. de Sotto Mayor Pizarro, "A nobreza portuguesa no período dionisino. Contextos e estratégias (1279-1325), En la España Medieval, 1999, n² 22, p. 100-101; Idem, D. Dinis, Lisboa, Círculo de Leitores, p. 197-199.

4 Uma temática acerca da qual, em 1967, Humberto Baquero Moreno afirmava ter havido "uma desatenção" por parte dos historiadores do direito e, tão-só, abordagens indirectas por 
o monarca tornava legítimo alguém que era filho natural, permitindo-lhe que pudesse ser herdeiro dos bens de seus pais e parentes e ainda que usufruísse das honras e dignidades dos fidalgos, como se tivesse sido concebido e nascido de pai e mãe "lídimos". Estas cartas agraciavam, portanto, pessoas cujo nascimento fora irregular, porque acontecera fora do casamento (sen casamento), e faziam com que essa mácula original (deffectum natalium) fosse relevada em tudo quanto dizia respeito à lei civil ${ }^{5}$.

Sustentados nesses numerosos documentos, procuraremos pois verificar como se desenvolve e afirma a legitimação pelo monarca no reinado de D. Dinis ${ }^{6}$.

parte dos historiadores ("Subsídios para o estudo da legitimação em Portugal na Idade Média. D. Afonso III a D. Duarte", Revista dos Estudos Gerais Universitários de Moçambique, vol. IV, Série V, 1967, p. 209-237, maxime p. 209). Trinta anos depois, Carla Maria de Sousa Amorim Teixeira considerava-a ainda uma "temática inédita na historiografia portuguesa" (Moralidade e costumes na sociedade de Além-Douro. 1433-1521 (a partir das legitimações), Porto, 1996, p. 3 - trabalho que completava um outro do mesmo ano, Sónia Maria de Sousa Amorim Teixeira, A vida privada entre Douro e Tejo: estudo das legitimações (1433-1521), Porto, 1996). A autora não deixava, no entanto, de apontar aquilo que, ao tempo, já se encontrava publicado: Humberto Baquero Moreno, Subsídios para o Estudo da Sociedade Medieval Portuguesa. Moralidade e Costumes. Dissertação de licenciatura em Ciências Histórico-Filosóficas apresentada à Faculdade de Letras da Universidade de Lisboa, 1961; Valentino Viegas, Subsídios para o Estudo das Legitimações Joaninas: 1383-1412, Odivelas, Heuris, 1984. Ainda que com um objectivo diverso, acrescente-se a posterior reflexão de José Mattoso, «Introdução: Legitimação e linhagem», e-Spania [En ligne], 11 juin 2011.

5 "E mando que a ley e o dereito que priva aqueles que nom son nados de liidimo casamento d'algumas cousas, que nom ajam em el logo nem lhy empeescan" (cfr., a título de exemplo, Chanc. D. Dinis, Liv. III, fl 99). Não esquecemos, aqui, a distinção entre os filhos naturais (nascidos anteriormente ao casamento ou durante a viuvez) e os bastardos (nascidos durante o casamento) - igualmente ilegítimos, no plano jurídico, mas resultantes de situações diferentes e assim consideradas no plano moral que condenava mais os segundos do que os primeiros (até pelo facto de os filhos dos eclesiásticos serem todos, necessariamente, naturais). Cremos, porém, que os nascidos antes do casamento eram legitimados pelo subsequente matrimónio dos pais, não carecendo, portanto, de qualquer outra legitimação régia.

6 Realce-se que esta temática, até hoje, ainda não foi objecto de um estudo de conjunto e, por isso mesmo, aqui apresentamos as primícias de uma reflexão global sobre as duas centenas de cartas de legitimação do reinado de D. Dinis - empreendimento que já temos em avançado estado de elaboração. Do mesmo modo, constitui matéria que, existindo certamente, no mesmo período, nos restantes Reinos peninsulares (cfr., infra, nota 36), parece não ter merecido ainda a atenção da historiografia espanhola. As nossas pesquisas pessoais foram infrutíferas e igualmente o foram as de Ermelindo Portela e de Pascoal Sopena, das Universidades de Santiago de Compostela e de Valladolid, aos quais aqui consignamos o nosso público reconhecimento e gratidão pelas diligências que eles próprios encetaram e cujos nulos resultados amavelmente nos comunicaram. 


\section{O poder de legitimar}

Torna-se evidente que ao tempo de D. Dinis, como explanaremos mais adiante, o direito de legitimar, a função de tornar legítimo o que havia nascido ilegítimo, estava reservado ao Rei. Mas desde quando os reis de Portugal se arrogaram esse direito? Cremos que terá sido a partir de D. Afonso III que a questão da legitimidade se terá colocado de uma forma pelo menos mais incisiva e que o direito e o dever de legitimar terá passado a estar reservado ao Rei, juiz supremo do Reino. É efectivamente neste reinado que surgem as primeiras cartas de legitimação de que temos notícia, podendo, eventualmente, terem-se perdido outras anteriores.

\section{Origens das cartas de legitimação}

Contudo, já nas doações que este monarca fez às suas barregãs, pelo menos às de mais elevada estirpe (Teresa Mendes de Sousa, Urraca Abril de Lumiares, Aldonça Anes da Maia, Teresa Fernandes de Seabra) ${ }^{7}$, ele próprio se preocupou em acautelar os direitos sucessórios dos filhos nascidos dessas ligações extraconjugais, direitos esses que, todavia, só se transmitiriam aos filhos legítimos desses bastardos - os de recta linea, ou per directam lineam, legitime descendentes; os herdeiros en dereyta linha decendentes. Não sabemos, porém, se, nestes casos concretos, os ilegítimos, para lograrem ser herdeiros, haveriam, previamente, de ser legitimados, por ele, Rei, ou por quem lhe sucedesse no trono, enquanto monarca. Na verdade, os textos são omissos quanto a essa hipótese:

"Et si post mortem vestram filius meus et vester vel filia mea et vestra vel filie et filii mei et vestri remanserint quos ego de vobis habuero habeant et possideant istam hereditatem supradictam cum omnibus juribus et pertinenciis suis in omnibus diebus vite sue et post mortem suam illi qui ab eis descenderant legitime habeant et possideant in pace ipsam hereditatem supradictam, cum omnibus juribus et pertinenciis suis. Et si meos filios et vestros vel meas filias et vestras quos vel quas de vobis habuero contigerit mori sine filio legitimo aut sine filia legitima supradicta hereditas post mortem eorum revertatur michi vel illi qui pro tempore regnaverit in regno Portugalie"».

7 Chancelaria de D. Afonso III, Livro I. Vol. 1, docs. 86, 99, 231, 389; Leontina Ventura, A Nobreza de Corte de Afonso III, 2 vols., Coimbra: Faculdade de Letras, 1992, vol. II, p. 541-545.

8 Vejam-se todos os documentos citados na nota anterior. 
Não se tratando de verdadeiras cartas de legitimação, estas doações inseriam em si esse conceito, porquanto o monarca capacitava os filhos nascidos dessa ligação, seus filhos ilegítimos, para receberem bens seus e para que os filhos legítimos deles um dia também os recebessem. Ou seja, a sua condição de ilegítimos, pelo menos no que tocava à herança de bens paternos, era ali completamente apagada.

De alguma forma esta situação confirmou-a e consolidou-a D. Afonso III nas doações que foi fazendo aos seus filhos e filhas bastardos: a elas no momento em que as dotava para casarem; a eles, porventura, no momento em que os armava cavaleiros ou em que lhes dava casa:

"do et concedo vobis donne Aleonor Alfonsi mee filie uxori donni Stephani Johannis et filiis et filiabus et nepotibus vestris quos vel quas legitimos vel legitimas habueritis et omnibus illis qui de vobis recta linea legitime descenderint villam meam que vocatur Pedroganum cum suis terminis et cum suis pertinenciis et cum omnibus juribus meis que ego in ipsa villa et in suis terminis habeo et habere debeo per directum. Ita tamen quod si vos donna Aleonor Alfonsi decesseritis sine filio vel filia vel sine filiis vel filiabus, vel sine nepote vel nepotibus legitimo vel legitima vel legitimis vel sine aliquibus qui de vobis recta linea legitime descendant, quod predicta villa de Pedrogano cum suis terminis et cum suis pertinenciis et cum omnibus suis juribus tam spiritualibus quam temporalibus ad me vel ad successores meos qui post me regnaverint in Regno Portugalie plene et libere revertatur. Si quis igitur hanc donationem meam integram servaverit benedictionibus dei et mei repleatur"9.

"do et concedo jure hereditario in perpetuum Martino Alfonsi filio meo filiis ac filiabus suis ab eo legitime descendentibus, omnes hereditates et possessiones quas ego habeo in Sanctarena (...) tali videlicet conditione quod si dictus Martinus Alfonsi mortuus fuerit, vel filii sui aut nepotes sui mortui fuerunt sine prole legitima ad me vel ad successorem meum, predicte hereditates et possessiones libere ac integre revertantur" 10 .

"et post mortem suam habeant et possideant illud, illi qui de eo legitime descenderint per directam lineam. Et si ipse Alfonsus mortuus

9 Chancelaria de D. Afonso III, Livro I. Vol. 2, docs. 456, 612.

${ }^{10}$ Chancelaria de D. Afonso III, Livro I. Vol. 2, doc. 514. 
fuerit sine filio legitimo vel sine filia legitima, predictum herdamentum revertatur ad me vel ad successores meos libere et integre, cum juribus, terminis et pertinenciis suis, sicut superius est expressum ${ }^{11}$.

Não resta qualquer dúvida de que, ao tempo de Afonso III, competia ao monarca, munido da sua regali et principali auctoritate, legitimar os filhos ilegítimos, ou seja, corrigir o seu defeito natal (legitimum facio et ipsum natalibus restituo), tornando-os capazes de gozarem dos direitos de herança, material ou social, a par com os outros filhos legítimos (ad omnes actus legitimos et ad successionem paternam una cum aliis filiis legitimis et heredibus). Admitidos e sancionados, pela legitimação e pela declaração formal e solene do Rei, ali mesmo, em plena Corte, os seus pais recebiam-nos como filhos legítimos. Ou adoptavam-nos como legítimos, quando não tinham outra descendência legítima, situação em que o Rei confirmava e validava a adopção e, recorrendo ao discurso directo, lhes sentenciava: "Sede filhos legítimos de vosso pai e seus legítimos sucessores" (estote filii legittimi patris vestri et legitimi successores).

\section{Primeiras cartas de legitimação}

Encontram-se apenas três cartas de legitimação em toda a Chancelaria de D. Afonso III, uma de 1265, outra de 1268 e uma outra de 1272 (a primeira e a terceira respondendo mais ao primeiro modelo e a segunda ao da adopção), outorgadas, respectivamente, em Coimbra, Leiria e Lisboa, o que, em termos geográficos, significa que as cartas de legitimação eram concedidas com normalidade, enquanto o monarca se deslocava pelo Reino. Regra geral, o pedido de legitimação era formulado pelo pai do legitimado. Nos três casos referidos, as petições foram feitas por Nuno Martins de Chacim, meirinho-mor do Reino, e pelos cavaleiros Pedro Martins Vilarinho e Pedro Soares Alvim, respectivamente. O primeiro é um oficial régio que estaria na Corte e aí mesmo teria apresentado a sua súplica (ad preces Nuni Martini) ao monarca, a fim de obter a almejada carta de legitimação; os demais, vindos de fora, dirigiram-se com esse objectivo específico à Corte, comparecendo diante do Rei (ad presenciam meam; perante me) e, com veemência, pediram-lhe (pettit a me cum instancia) que tornasse seus filhos ilegítimos em seus legítimos herdeiros (facere in omnibus bonis suis legittimum successorem).

A primeira e a última carta, dadas respectivamente a Nuno Martins de Chacim e Pero Soares Alvim, ou aos seus filhos Rodrigo Nunes de Chacim e João de

${ }^{11}$ Ibidem, Livro I. Vol. 2, docs. 514, 623, 735. 
Lobeira, são concedidas, atendendo aos pedidos (precibus inclinatus) e por graça especial (de speciali gratia), em troca de serviços prestados: num caso, o serviço "oficial", na Corte, no exercício do novel cargo de meirinho-mor do Reino; no outro, os méritos da lealdade e da fidelidade de um já longo serviço despendido na Cúria tanto ao Rei como a seus filhos ${ }^{12}$.

Tendo em atenção que a primeira carta foi concedida justamente ao filho do meirinho-mor, poderá aventar-se a hipótese de ele, enquanto oficial de justiça de maior relevo, estar relacionado com o início deste processo por parte do monarca. Tendo-se originado naqueles embriões que foram as cartas de doação a algumas das suas barregãs, as cartas de legitimação terão, em nosso entender, passado para fora do âmbito da família do Rei e entrado na esfera da nobreza por via do meirinho-mor ${ }^{13}$.

Não podemos, contudo, afirmá-lo com absoluta segurança.

${ }^{12}$ Recorde-se que João de Lobeira (1233-1285) foi um trovador galaico-português da Corte de Afonso III. Está representado no Cancioneiro da Biblioteca Nacional com cinco textos e é apontado como o primeiro autor em prosa do Amadis de Gaula. Cremos que se contava entre os vassalos que constituíam a casa que D. Afonso III pôs a seu filho, o infante D. Afonso, e que estava presente na doação que lhe fez do castelo da Lourinhã, em 5 de Fevereiro de 1278. Acerca dele Carolina Michaëlis de Vasconcelos (A saudade portuguesa, Guimarães Editores, Lisboa, 1996, p. 80-82) chegou a afirmar que era homem culto, porventura versado na literatura francesa e que talvez até tivesse andado por França. Não decerto com o conde de Boulogne (futuro Rei D. Afonso III) que regressou a Portugal em 1246. Mas o facto de o monarca já na carta de legitimação relevar os serviços prestados pelo pai de João de Lobeira e por ele próprio pode significar que seria adulto quando a recebeu (talvez perto da morte de seu pai, justamente para poder herdar). Cfr., a propósito deste trovador, António Resende de Oliveira, Depois do Espectáculo Trovadoresco. Estrutura dos cancioneiros peninsulares e as recolhas dos séculos XIII-XIV, Coimbra: Edições Colibri, 1994, p. 365-366; idem, "Distracções e Cultura", in Leontina Ventura, D. Afonso III, Lisboa: Círculo de Leitores, 2006, p. 227 e 257. Para outros elementos biográficos, veja-se José Augusto Pizarro, Linhagens Medievais Portuguesas. Genealogias e Estratégias (1279-1325), 3 vols., Porto, Centro de Estudos de Genealogia, Heráldica e História da Família, 1999, vol. I, p. 576-577.

${ }^{13}$ É de salientar que uma lei de Afonso III, de 1261, ano da criação do cargo de meirinho-mor, estabelecia que "os filhos das barregãas nom uaam aos Moesteiros nem aas eigreias nem aos testamentos senom forem Recebudos nos beens dos padres assy como filhos lijdemos" (Livro das Leis e Posturas, edição de Maria Teresa Campos Rodrigues, Lisboa: CML, 1974, p. 143). E estatuía, também, "que o Meyrinho faça pagar aos Moesteiros e aas eigreias todalas cousas que os filhos das barregãas que nom ssom erdados nos beens dos padres assy como filhos lijdemos despenderem ou filharem ou danarem ou Roubarem dos Moesteiros ou das eigreias ou dos homens das herdades delas ou o que ouuerom per pedidas assy como erdeiros e padrões desse tempo do degredo" (ibidem, p. 145). 


\section{As cartas de legitimação no reinado de D. Dinis}

Sabemos, porém, que D. Dins, que teve de ser legitimado pelo papa, como já se disse, legitima ele mesmo, enquanto soberano, não apenas os seus filhos bastardos e parentes, vassalos e filhos de leigos (cavaleiros e escudeiros e outros), mas também os filhos de eclesiásticos - de monjas, freiras e abadessas; de clérigos de missa, cónegos, arcediagos, tesoureiros, chantres e deões; de freires, priores e abades e, até, de bispos. Deixou-nos um vasto conjunto de cartas de legitimação, que se revestem de uma enorme importância para o estudo das relações dos celibatários leigos e eclesiásticos, das ligações pré-matrimoniais, do adultério, da viuvez, do comportamento sexual do clero, para além de permitirem a clarificação das estratégias matrimoniais na sociedade portuguesa e de evidenciarem o elevadíssimo número de uniões ilegítimas ${ }^{14}$.

Por ora, não nos é fácil explicar as razões por que D. Dinis, tendo tomado conta do poder em 1279, só em finais de 1285, e estando em Castelo Branco, vai aceder à concessão da primeira carta de legitimação conhecida. $\mathrm{O}$ agraciado é Martim Nunes de Barbosa, apontando-se como razões para a outorga de tal mercê os seus próprios méritos e a insistência com que a impetrou seu tio Fernando Peres de Barbosa, então presente na Corte onde ocupou altos cargos durante meio século, e também porque já era falecido Nuno Peres de Barbosa, seu pai. A esta situação verdadeiramente singular talvez não seja alheio um conjunto de circunstâncias sucessivamente ocorridas de que, para além de alguma eventual perda de documentação, acidental ou deliberada, são marcos principais: o facto de Martim Nunes, ultrapassado esse impedimento de nascimento, ser então o putativo herdeiro da linhagem dos Barbosas, em plena ascensão na Corte; a coetânea morte de D. Gonçalo Garcia de Sousa, seu parente, cuja herança veio a ser tão disputada ${ }^{15}$; o acordo estabelecido entre o Rei e os bispos em 1282; a famosa revogação a que o monarca procede em Dezembro 1283 das doações que fizera quando era de "pequena idade"; por fim,

${ }^{14}$ A elevada incidência de uniões ilegítimas, logo, de filhos fora do casamento, durante o reinado de D. Dinis foi já realçada por José Augusto Pizarro (“A nobreza portuguesa no período dionisino. Contexto e estratégias (1279-1325)”, En la España Medieval, Madrid: Universidad Complutense, $\mathrm{n}^{\circ} 22$ (1999), p. 75). O índice de 10,4\%, registado no século XII, elevou-se para $17,1 \%$ no século XIII, tendo-se mantido nos $12,1 \%$ na primeira metade do séc. XIV. Estes números provam que as restrições ao casamento legítimo, em especial no século XIII, provocavam o incremento da barregania e o consequente aumento dos filhos ilegítimos $(5,3 \%$ no século XII, $9,8 \%$ no século XIII e $11,9 \%$ no séc. XIV).

${ }^{15}$ Cf. Luis Krus, "O rei herdeiro dos condes: D. Dinis e a herança dos Sousas”, in Passado, memória e poder na sociedade medieval portuguesa. Estudos, Redondo, Patrimonia, 1994, p. 59-99. 
a afirmação, ainda incipiente mas firme, da autoridade régia. Após esta carta de 1285, irão passar-se quatro anos durante os quais não há notícia de nenhuma outra carta de legitimação ter sido concedida. Um afã legitimador inicia-se em $1289^{16}$ e durará, embora de forma irregular, até ao final do reinado, atingindo no total as duas centenas de cartas de legitimação, cartas de privilégio, de graça e mercê, que representam, em si mesmas, uma clara afirmação do poder régio. Por via delas, e na sequência de assertivas medidas centralizadoras que vinha tomando, o Rei, evocando o fundamento jurídico do seu poder (de meu poder e de mha graça special), confere uma graça particular, com base no seu próprio juízo de valor (por que acho que eles som boons e de boom testemoynho e de boa fama) e tendo em conta serviços a ele prestados (por muyto serviço que mi fizerom) e, também, o serviço de Deus (fazer esta mercê e esta graça por serviço de Deus). Como que o Rei exerce aqui um papel de mediador entre o homem e Deus ${ }^{17}$, porque legitima e implanta os bastardos, fruto da imoralidade e do pecado dos homens, na sociedade daquele tempo ${ }^{18}$. Apesar da irregularidade de nascimento, a dispensa e legitimação régia introduz pelo menos - ou sobretudo, no que toca aos eclesiásticos - uma preocupação de teor moralista, atendendo às funções que desempenham. A recuperação das honras e dignidades, por parte do legitimado, facilitaria a reabilitação social e moral aos olhos da sociedade, muito embora vejamos nos objectivos destas cartas sobretudo razões de ordem social e económica - a possibilidade de transmitir os bens, as honras e os

${ }^{16}$ Cremos que tenha havido uma relativamente grande contenção legislativa até à assinatura da Concordata de 1289. Todas as esperanças estavam depositadas nela e o Rei não queria dar qualquer passo em falso que pudesse desagradar à Santa Sé. Depois de assinalada, o monarca sentiu outra amplitude de acção e, a pouco e pouco, foi legislando sobre novos domínios, geralmente à medida que eles iam surgindo, ou seja, ad hoc. A Concordata é de Fevereiro de 1289 e a segunda carta de legitimação é precisamente de 26 de Fevereiro de 1289, havendo, anteriormente, apenas o caso, absolutamente excepcional e isolado, em finais de 1285 , de Martim Nunes de Barbosa (ANTT - Chancelaria de D. Dinis, Livro I, fl. 251). Cfr. Livro das Leis e Posturas, p. 340-358, 363-370; António Domingues da Sousa Costa, "As Concordatas portuguesas", Itinerarium, ano 12, n⿳ 51 (1966), p. 24-46; idem, "D. Frei Tello, arcebispo-primaz, e as concordatas de D. Dinis", in IX Centenário da Dedicação da Sé de Braga. Congresso Internacional. Actas, II/1 Braga (1990), p. 283-316; Fernando Félix Lopes, “A propósito do conflito entre a Igreja e Portugal no tempo de D. Dinis" [1964], in F. F. LOPES, Colectânea de Estudos de História e Literatura, III, Lisboa, 1997, p. 185-94.

${ }^{17}$ Carla Amorim Teixeira, op. cit, p. 12.

${ }^{18}$ Idem, ibidem, p. 12-13. Embora seja de D. Afonso IV, recordamos aqui a lei que este publicou contra os homens casados que tiverem barregãs "e teem essas barragaans pubicamente de que se sege maao enxempro e deserviço de deus e del Rey" (Ordenações del Rei Dom Duarte. Edição preparada por Martim de Albuquerque e Eduardo Borges Nnues, Lisboa, Fundação Calouste Gulbenkian, 1988, p. 372-373). 
privilégios à descendência ${ }^{19}$. A instituição de morgadios, ou seja, de propriedades vinculadas à sucessão no mais velho dos filhos varões legítimos, que é semelhante à sucessão régia, por garantir ao chefe da linha um desafogo económico correspondente ao seu nível social, e que alcança um grande desenvolvimento precisamente durante o reinado de D. Dinis, também não pode ter deixado de influir na petição de algumas destas cartas ${ }^{20}$. A legitimação faz-se sobretudo por causa dos bens, pois eles são a verdadeira base da honra, sustentáculo imprescindível da nobreza. Podendo, num ou noutro caso, fazer-se alusão à ausência de filhos legítimos, é a possibilidade de transmissão dos bens à descendência que justifica a impetração de uma carta de legitimação, razão pela qual a maior parte delas, ou dos pedidos, são de pais oriundos do clero ou da nobreza ${ }^{21}$. Por via dela, e de acordo com a vontade expressa aquando do seu requerimento, os legitimados poderiam herdar do pai, da mãe, "do padre como da madre", "de seu padre e de seus irmãos e de seus parentes e de seus cunhados", "de seus padres e dos seus parentes mais chegados".

${ }^{19}$ Na mesma linha de seu pai, em 16 de Junho de 1297, D. Dinis publica uma lei proibindo os "fidalgos que nom som lijdemos que nom devem comer nos moesteyros nem nas Egreias": “(...) tenho por bem e mando e defendo que nenhu homem nem nenhua molher que nom forem lijdemos que nom pousem nem sse chamem nos mõesteyros nem nas egreias nem lhis dem ende caualarias nem casamentos pero uos mostrarem mhas cartas per que os legitimasse mando que lhis nom ualham contra os mõesteyros e Egreias ca eu entendo que o nom posso fazer de dereyto e que he prijgoo de mha alma. e eu querendo deus en ai lhis farey bem e merçee ca a legitimaçom entendesse no leygal e em auerem honra en ssas pessoas como outros filhos dalgo lijdemos" (Livro das Leis e Posturas, p. 196).

${ }^{20}$ Um bom exemplo disso foi o passado com Vasco Peres Farinha. Depois de se ter envolvido em contendas com os filhos do irmão mais velho, já falecido, readquire os bens de Góis e solicita, em 16 de Outubro de 1289 (TT-Chanc. D. Dinis, Liv. 1º fl. 265-265v), a legitimação de Gonçalo Vasques, seu filho mais velho (de entre os vários que teve de Marinha Peres, abadessa de Ferreira d'Aves), e, a 5 de Junho de 1290, institui em favor deste o morgadio de Góis (TT Viscondes de Vila Nova de Cerveira, cx.43, n. ${ }^{\circ}$ 59). Este caso é tratado por Maria de Lurdes Rosa, O morgadio em Portugal, séculos XIV-XV. Modelos e práticas de comportamento linhagístico (dissertação de mestrado), Lisboa, Lisboa, Ed. Estampa, 1995, p. 55-56, muito embora a autora incorra em algumas imprecisões de datas, agora corrigidas, decerto por não ter tido acesso directo aos documentos.

${ }^{21} \mathrm{O}$ que, segundo Paulo Merêa, se justifica pelo simples facto de as nossas leis apenas concederem direitos de sucessão aos filhos naturais de plebeus ("Perfilhação - achega para um dicionário histórico da Língua Portuguesa", Revista Portuguesa de Filologia, vol. VII (1956), p. 118-127). 
Uma das primeiras cartas é exactamente concedida a uma freira, ou melhor, à abadessa de Lorvão ${ }^{22}$, Teresa Mendes de Sousa, em 11 de Março de $1292^{23}$. Cremos que teria sido precisamente esta sua solicitação, sendo aquela - da mais elevada estirpe, antiga barregã de D. Afonso III - porventura mãe de algum meio-irmão de D. Dinis, a justificação da criação ex professo de uma lei, para legitimar o seu caso, designada por: "Da ligitimaçom dos filhos dalgo e das donas dordis"24:

"Don denys etc. A quantos esta carta uirem faço saber que como tal monia ou tal dona uehesse a mjm e me dissesse [haver] huum filho de tal que assy nome Essa dona me pediu por merçe e por graça que eu que lhe legetimasse o dicto filho que pela mha legitimaçon podesse seer herdeyro nos seus bees dela e de seus parentes quando mester fosse. e que possa auer honrras de dignydades de filhos dalgo assy como se fosse feyto e nado lijdemamente Eu sobre estas cousas e sobre esta ligitimaçom que me esta dona pidiu detiuy por ben de lhe fazer esta merçe e esta graça por seruiço de deus e Recebo essa petiçon E legitimo e faço o dicto seu filho lijdimo de meu poder e de mha graça / special. E daquy adeante mando e outorgo que o dicto seu filho aia e Seia herdeyro en bees da dicta dona sa madre e de seus parentes quando lhe acaeçer assy como se fosse nado lijdimo. E mando e outorgo que aia honrras e dignydades en todalas outras cousas que deue a auer filho lijdimo. E sse alguua ley ou dereyto ou custume hy a que contra esta

${ }^{22} \mathrm{O}$ documento refere-a como monja, enquanto o Livro de Linhagens do Conde D. Pedro ( $L L$ 41L5) a menciona como abadessa. Trata-se, por certo, da que citámos acima como barregã de D. Afonso III. Cfr. Leontina Ventura, A Nobreza de Corte de D. Afonso III, vol. II, p. 543; Chancelaria de D. Afonso III, Livro I. vol. 1, doc. 86.

${ }^{23}$ Esta é, afinal, a data da concessão do privilégio por D. Dinis. A petição, tal como a lei, será anterior, porventura do ano antecedente, pouco posterior a 21 de Março de 1291, data de uma outra lei, em que o monarca permite aos que entrarem em ordens, que estes, à sua morte, não tenham parte nos seus bens, muito embora aqueles possam dar-lhes algo pela sua alma, sendo-lhes, para tanto, permitido vender o terço dos seus herdamentos e possessões, mas tão-só a quem nunca os possa fazer voltar às ordens, ficando as outras duas partes a seus herdeiros (desde que não sejam frades nem freiras nem donas de ordem). E se não houver herdeiros legítimos, ordenem e façam com que esses herdamentos e possessões fiquem a quem considerarem, desde que, depois, não fiquem às ordens (cfr. Livro das Leis e Posturas, p. 73-74).

${ }^{24}$ Livro das Leis e Posturas, p. 126-127. Note-se que o texto desta lei sobre o assunto, retirados os nomes, é exactamente o da carta de mercê concedida a D. Teresa Mendes para seu filho Gonçalo Peres, que ela teve de Pero Afonso Ribeiro. É com base nessa similitude que propomos para o referido texto, que figura no Livro das Leis e Posturas com a ampla data crítica de [1279-1325], uma datação pouco anterior a 11 de Março de 1292. 
mha legitimaçom Seia mando que lhe nom enpeesca nem aquela ley do Codigo que falla no Titolo dos testamentos que nom son ben feytos que se começa conqueritur E o outentico que sse começa Nouissima ect. Entensso. Ect”

Por outro lado, é o único exemplo em que a petição da mãe é seguida por uma outra, do mesmo dia, apresentada pelo pai do legitimado - Pero Afonso Ribeiro, que, recorde-se, era vassalo régio e, reforce-se, era tutor dos bastardos régios, Afonso Sanches e Pedro Afonso - e pelos irmãos legítimos. Muito embora tenhamos no nosso corpus documental mais quatro cartas concedidas a filhos de freiras ou abadessas (duas para dois filhos de Marinha Peres, abadessa de Ferreira de Aves, uma para um filho de Aldonça Martins, abadessa de Tarouquela, e outra para um de Ouroana Martins, abadessa de Loivo) aquele é o único pedido feito pela mãe. A maior percentagem pertence àquelas cujo impetrante é o pai, havendo, porém, casos de legitimações solicitadas por irmãos ou mesmo por meios-irmãos, ou seja, irmãos legítimos, o que pode até parecer estranho, pois, dessa forma, pelo menos teoricamente, o legitimado passava a ter os mesmos direitos que eles à herança paterna. É o caso de João Vasques Pimentel, cujo pedido foi apresentado por seus meios-irmãos, Fernão Vasques e Estêvão Vasques ${ }^{25}$, ou de Rodrigo Anes de Sedielos, a rogo de seu pai e de sua mulher legítima, mas também de seus irmão Afonso e Guiomar Anes. O afecto nascido entre eles, fruto de uma criação em comum no lar paterno, pode ser uma forte razão para este procedimento. Há, ainda, várias legitimações feitas a "pidimento e a rogo de alguns da sua linhagem" que não são propriamente identificados ${ }^{26}$, e uma ou outra "a prazimento de seus hirmãaos e de seu linhagem" 27 .

Constam do nosso corpus documental cerca de trinta cartas concedidas a filhos de eclesiásticos, perto de quarenta a filhos de nobres (entre os quais um filho bastardo do próprio Rei D. Dinis), outras tantas a filhos de cavaleiros e escudeiros, mais de seis dezenas a filhos de outros que, sendo com certeza

${ }^{25}$ Bernardo de Vasconcelos e Sousa, Os Pimentéis: percursos de uma linhagem da nobreza medieval portuguesa: séculos XIII-XV. Lisboa: Imprensa Nacional-Casa da Moeda, 2000, p. 402-403.

${ }^{26}$ ANTT - Chancelaria de D. Dinis, Liv. 2o , fls. 102v (1295 Maio 17, Coimbra), 103 (1295 Maio, 18, Coimbra), 104v-105 (1295 Junho 1, Coimbra), 107-107v (1295 Junho 19, Lamego), 108 (1295 Junho 20, Lamego), 109v (1295 Junho 30, Trancoso).

${ }^{27}$ É o caso da legitimação de Martim Redondo, filho de Martim Anes Redondo e de Teresa Mendes, que, para além da solicitação e do "prazimento" de Rodrigo Anes Redondo, decerto seu tio, teve também a dos seus irmãos e da sua linhagem (Ibidem, Liv. 3 ${ }^{\circ}$, fl. 56v (1307 Agosto 16, Lisboa)). 
nobres, não são devidamente enquadrados nas cartas que os referem. É de realçar que algumas destas cartas conferem a legitimidade a mais do que um filho, verificando-se que os anos de maior incidência são os de 1292 (com 16), 1295 (com 14), 1312 (com 10) e 1320 (com 16). Releve-se, também, o facto de as referidas cartas serem maioritariamente concedidas a varões: quase duas centenas de homens e pouco mais de uma dezena de mulheres.

Algumas vezes a legitimação régia é precedida por uma adopção ou perfilhação, registada em instrumento público, com o nome do tabelião, em que o perfilhado é recebido "por filho lídimo e herdeiro em todalas naturas e honras e testados". Os exemplos que temos levam-nos a afirmar que estas ocorrem em níveis mais baixos da nobreza, escudeiros em especial, provavelmente gente mediana e moradora em pequenas terras distantes, com achaques ou muito idosa, que não se podia dirigir pessoalmente ao Rei. Uma ou outra vez são, simultaneamente com os progenitores, recebidos por seus irmãos. Pertencem a este número os casos de Pero Rodrigues, escudeiro, recebido como filho por seus pais Rui Peres de Arga e Estevainha Anes de Trás Lamas e como irmão lídimo e herdeiro por Gonçalo Rodrigues (e sua mulher Mor Martins), filho do mesmo Rui Peres e de sua mulher legítima Estevainha Vasques $^{28}$; de Rodrigo Anes, escudeiro, filho de João Fernandes de Sedielos e de Teresa Gonçalves, recebido como filho carnal e herdeiro por seu pai e sua mulher legítima Constança Lourenço, a rogo de seus irmãos Guiomar Anes e Afonso Anes ${ }^{29}$; e de Pero Fernandes recebido por Mateus Fernandes, clérigo ${ }^{30}$. Outros recebem os seus filhos ou netos perante o Rei. Exemplo disso é João Velho de Pedregais, que recebeu por neto João Fernandes, filho de Fernando Soveral e de sua filha Maria Anes Moura ${ }^{31}$. É ainda o caso de Lourenço Anes Taleigas filho de João Afonso Taleigas e de Urraca Anes que o receberam ${ }^{32}$; o de Pero Martins, filho de Martim Pais, cavaleiro de Ferreira de Aves, que, com seu genro, Pero Gonçalves de Rial, e sua filha, Alda Martins, o receberam por filho e irmão lídimo ${ }^{33}$; o de Vasco Anes, filho de João Gulfar cavaleiro da Maia e de Maria Esteves de Vila Nova, do julgado de Vermoim, pois não havia outro filho lídimo nem herdeiro ${ }^{34}$. Referência interessante encontra-se no caso de Gomes Fernandes, filho de Fernando Moniz escudeiro d'Olo, que o recebeu

\footnotetext{
${ }^{28}$ ANTT - Chancelaria de D. Dinis, Liv. $2^{\circ}$, fl. 109 (1295 Junho 18, Lamego).

${ }^{29}$ Ibidem, Liv. $2^{\circ}$, fl. 111v (1295 Agosto 15, Guarda).

${ }^{30}$ Ibidem, Liv. $2^{\circ}$, fl. 115v-116 (1295 Setembro 17, Guarda).

${ }^{31}$ Ibidem, Liv. 2 ${ }^{\circ}$, fl. 1116-116v (1295 Dezembro 3, Beja).

${ }^{32}$ Ibidem, Liv. $3^{\circ}$, fl. $54 v$ (1307 Maio 31, Lisboa).

${ }^{33}$ Ibidem, Liv. $3^{\circ}$, fl. 83v (1313 Outubro 3, Lisboa).

${ }^{34}$ Ibidem, Liv. $3^{\text {o }}$, fl. 123 (1319 Janeiro 10, Montemor-o-Novo).
} 
"por seu filho e por seu herel e o herdou" perante o Rei e "outros hereeos de linha" 35 .Casos há em que um pai - Fernando Rodrigues Bugalho, vassalo régio - pede a legitimação para vários filhos, havidos em diferentes mulheres.

No fundo, com estas inúmeras cartas, o Rei, que recorreu às armas para submeter o seu irmão e às Inquirições para controlar o poder senhorial, e que interveio nas partilhas das famílias nobres, arrogando-se o direito de interferir no património senhorial, reserva-se também o poder e a graça de, no que toca à jurisdição temporal, legitimar os filhos de matrimónios ilegítimos ${ }^{36}$. Sustentado na sua régia potestade, afirma que todas as disposições gerais sobre o assunto serão embargadas - manda que "aquel dereyto que e feyto contra aqueles que non som liidimos e que os priva das dignidades e das sucessões e das heranças e das onrras e das outras cousas que nom aja logo em este(s)". Ou, no caso específico da abadessa de Lorvão, pronuncia que "se alguma ley ou dereyto ou costume hy a que contra esta mha legitimaçom seja que lhy nom empeesca". E manda, ainda, "que lhy nom empeesca aquela ley do Codigo que fala en o título dos testamentos que nom som bem feytos". O monarca sublinha, pois, que anula as disposições do Direito Civil e dos usos e costumes do Reino, e mesmo de outras leis de Imperadores, no que se refere à bastardia. O Rei, concessor da carta de legitimação de acordo com a sua vontade, derroga qualquer norma contrária no que concerne à ilegitimidade. Inviabilizava, assim, todas as leis do direito consuetudinário e romano, inibidoras ou proibitivas da doação de bens, da aquisição da honra e de prerrogativas sociais e económicas por parte dos filhos bastardos. Resguarda, no entanto, o direito dos filhos legítimos à herança paterna, pois não é sua "temçam" ou o seu "entendimento nom foy nem he que per razom deste legitimaçom tolhesse nenhuma rem do seu dereyto". Assim respondia, em 27 de Março de 1292, em Alenquer, à queixa apresentada por Afonso Esteves, prior de Arouce, que temia que, por causa da legitimação

${ }^{35}$ Ibidem, Liv. $2^{\circ}$, fl. 36 (1292 Julho 7, Santo Estêvão de Riba Lima).

${ }^{36}$ Trata-se de uma prática seguida por Afonso X, de Castela, objecto de normativa presente na quarta partida (referente ao direito de família), no título En que manera puedan los Emperadores, e los Reys els Apostoligos, legitimar los fijos que non som legitimos: "Piden merced los omes a los Emperadores, e los Reyes en cuyo Señorio biven, que les fagan sus fijos, que han de barraganas, legitimos. E si caben su ruego, e los legitimam, son dende adelante legitimos, e han todas las honrras, e los proes que han los fijos que nascen de casamiento derecho. Otrosi el Papa puede legitimar a todo ome que sea libre, quier sea fijo de Clerigo, o de lego; de guisa, que pueden ser Clerigos los que legitimare, e sobir e aver Dignidades. [...] E maguer dispensasse com ellos, para aver Ordenes, e las otras coisas sobredichas, non puede dispensar con ellos, quanto en las cosas temporales; fueras ende, si fuesen de su temporal juridiction. Esto mismo es, si el Emperador, o el Rey, legitimasse algunos; ca maguer dispense con ellos quanto en la temporal juridiction, non lo puede fazer en las cosas spirituales, que pueden ser Clerigos, o Beneficiados". 
de Gonçalo Vasques, filho de Vasco Peres Farinha e de Marinha Peres, abadessa de Ferreira de Aves, ele perdesse o direito que tinha em Góis. ${ }^{37}$

Em um ou outro caso, o monarca permite ainda, expressamente, por via destas cartas de legitimação, o gozo de uma importante prerrogativa da nobreza: a possibilidade de "retar": "dou lhy comprido poder que el possa dizer e retar o mal que a el ou a alguum do seu linhagem fezerem assi como o podem dizer aqueles que son filhos d'algo liidimos e direitos e que nom an embargo nenhuum" (caso das cartas concedidas aos filhos de Nuno Fernandes, Aires Nunes e Rui Nunes) ${ }^{38}$. Note-se que se trata de um privilégio de relevo, justamente num tempo em que o monarca legislava contra as assuadas, contra a vindicta privada, num denodado percurso a caminho do controlo da violência.

Atentando às características formais dos diplomas em apreço, estamos perante cartas abertas que se iniciam com a intitulação régia ("Dom Denis pela graça de Deus Rey de Portugal e do Algarve"), a que se segue o endereço ("A todos aqueles que esta carta virem"), a notificação ("faço saber que querendo fazer graça e mercee"), a classificação da carta ("de graça e mercê") ${ }^{39}$. O texto contém a identificação do(a) legitimado(a) - em alguns casos classificado, aos olhos régios, como sendo "boom, de boom testemoynho e de boa fama" ou que "era tal que merecia onrra" -, de seus progenitores, de quem, na maior parte dos casos, são revelados estatutos e funções, às vezes a naturalidade, após o que se refere quem foi o, ou os, impetrante da petição de legitimação ${ }^{40}$ e a forma como foi feita, seguindo-se, depois, a parte dispositiva: "legitimoo

${ }^{37}$ ANTT - Chancelaria de D. Dinis, Liv. $2^{\circ}$, fl. 28v.

${ }^{38}$ Ibidem, Liv. $3^{\circ}$, fls. 64v e 65 (1308 Agosto 29, Gaia). É nestas cartas que, pela primeira vez, o Rei emprega uma expressão que vai utilizar habitualmente para dar conta que estes filhos foram nascidos fora do casamento, pois, referindo os pais, diz sempre "sen casamento". ANTT - Chancelaria de D. Dinis, Liv. 3º fl. 94v (1315 Janeiro 26, Borba).

${ }^{39}$ Só a que foi concedida a seus sobrinhos, filhos do infante Afonso, é que é designada por "graça e bem e mercee".

${ }^{40}$ Excluídos os casos do monarca e de seu irmão, encontramos, entre os laicos que impetram cartas de legitimação, vassalos do Rei (Vasco Peres Farinha, Gonçalo Velho de Sequeira, Lopo Soares de Alvarenga), cavaleiros (Mendo Mendes, cavaleiro de Bragança, Gomes Fernandes do Vale, Estêvão Anes Tedom, Egas Afonso, cavaleiro de Riba Tâmega, Fernão Mendes, cavaleiro de Castro, João Fernnades, cavaleiro de Sedielos, João Martins, cavaleiro de Cunha, Vasco Fernandes, cavaleiro de Talheiras, Martim Pais, cavaleiro de Ferreira, Rui Fernandes, alcaide de Azambuja, Afonso Anes de Paiva, Lourenço Vasques, cavaleiro de Fonseca, João Gulfar, cavaleiro da Maia, Estêvão Martins de Alvelos), escudeiros (Fernão Moniz, escudeiro de Ollo), um ouvidor do Rei nos feitos crime (Rui Nunes) e um procurador régio de Braga (Domingos Pais). 
e façoo liidimo que pela mha legitimaçom possa aver testamentos e naturas e sucessões e dinidades e todalas onrras que filho d'algo possa aver assy como se fosse feyto liidimamente", inserindo-se, aqui, a cláusula derrogatória. Termina com a subscrição directa (só no caso da legitimação dos filhos do irmão Afonso e do filho de Martim Correia), ou indirecta, com a referência dos nomes do desembargador e do escrivão.

Estas cartas são outorgadas nos locais onde o Rei estadia, às vezes mesmo em arraiais, como é o caso do de Portalegre, em Agosto de 1299, e do de Coimbra, em Março de 1322, ali por via do conflito com seu irmão, aqui em guerra civil com seu filho. Uma circunstância anómala que, levando-nos a pensar que não seria o momento mais indicado para a concessão destas cartas de legitimação, talvez possa reflectir a tentativa, por parte do Rei, de conseguir a adesão de partidários através deste expediente.

Nada sabemos quanto à idade dos legitimados e também quanto às mães deles. Estes filhos podem ser fruto de casos incestuosos, de violações ou de outros abusos ${ }^{41}$. São, indubitavelmente, concepções concretizadas de forma ilegítima, "sen casamento", e é por isso, que, pela legitimação, o Rei os capacita como "se fosse feyto e nado liidimamente".

O mesmo se pode afirmar das freiras e dos clérigos. Diz-se de algumas que eram abadessas, mas sê-lo-iam já na altura do "caso"? Outros eram "cónegos", mas isso significa que já o eram na altura, ou que o são no momento da legitimação? Inclinamo-nos para esta última hipótese.

D. Dinis, como filho mais velho do Rei, estava destinado a reinar. Por isso, as diligências para o legitimar começaram logo que ele nasceu. Nos casos que analisámos, talvez se trate, quase, do inverso. É provavelmente próximo da hora da morte, ou muito adiantados na vida, que o pai ou a mãe, vendo-se sem descendentes legítimos e sem hipótese de os vir já a ter, se lança na procura da legitimação de um seu descendente bastardo. Também se pode imaginar que, em certas ocasiões, a descendência legítima faltou abruptamente e foi necessário recorrer à ilegítima para perpetuação da estirpe. O facto de algumas vezes, como vimos, ser o avô o impetrante, poderá mesmo revelar a morte do progenitor. Obviamente que haverá excepção de casos de pura afeição, como

\footnotetext{
${ }^{41}$ Não poderemos esquecer que as delongas e o elevado custo que implicava a obtenção de dispensas de impedimentos matrimoniais devido à existência de parentesco entre os nubentes, em grau proibido pela Igreja e numa época em que se levantavam obstáculos ao casamento, mesmo entre parentes afastados, podem estar na origem do nascimento de alguns filhos ilegítimos.
} 
é o dos bastardos de D. Dinis e, porventura, de alguns outros em que até os irmãos legítimos vêm implorar a legitimação deles.

O que acabamos de apresentar não é senão uma primeira abordagem à temática das legitimações régias de D. Dinis. Estamos no início. Seguro é que se legitima um filho para ele ter acesso à sua parte da herança. O estatuto social de seus pais permite pressupor um conjunto de factores (sociais, económicos, religiosos, afectivos, sexuais, éticos) que terão contribuído para o nascimento de tantos filhos fora do casamento. As mais diversas linhagens - dos Abreus, Alcoforados, Alvarengas, Alvelos, Arões, Azevedos, Barbosas, Barrosos, Braganças, Brandões, Bugalhos, Cambras, Casais, Correias, Cunhas, Espinhos, Farinhas, Fonsecas, Froiões, Gundares, Laínhas, Leitões, Maias, Molnes, Paivas, Pereiras, Portocarreiros, Redondos, Resendes, Ribeiros, Sequeiras, Tavares, Teixeiras, Vasconcelos, Vilarinhos, Zamoras, Zotes, e outras - impetraram ao monarca uma ou mais cartas de legitimação para o(s) seu(s) filho(s) ilegítimo(s).

O número considerável de filhos de clérigos resultará, sem grande margem para dúvidas, do facto de terem sido marginalizados (se não excluídos) do modelo familiar, por imposição de princípios linhagísticos e patrimoniais, que não de uma escolha pessoal e reflectida da vida religiosa.

Porém, o tema das legitimações suscita muitas questões que ainda ficarão, por ora, em aberto: qual o real sentido de "mulher solteira"? Porque é que expressões como "mulher solteira" e "sen casamento" só aparecem a partir de certa altura? Qual a razão de ser de certos fluxos de legitimações em determinados anos? Com que idade se era legitimado? Porque é que os filhos e filhas do infante D. Afonso foram legitimados, digamos, em conjunto, sem sequer se mencionarem os seus nomes e, inclusivamente, podendo tratar-se de uma legitimação que, a priori, iria servir até para aqueles que ainda pudessem vir a nascer? Como explicar um outro caso (esporádico, é certo) de legitimado que nem nome tem, dele se dizendo apenas que é o filho de Fulano? Que não havia legítimos e que, mesmo entre os ilegítimos, ele era o único? Que certos filhos ilegítimos eram trazidos para a casa paterna e outros eram deixados à sua sorte em casa das mães, geralmente de condição inferior? Será lícito pensar que os legitimados eram sempre aqueles que tinham vivido no seio da família paterna, família nobre, e nele tinham adquirido a educação própria da nobreza? Será que a carta de legitimação, atribuída por rescrito régio, concedeu, na prática, no que toca à transmissão patrimonial, as mesmas prerrogativas e direitos jurídicos conferidos aos filhos nascidos do matrimónio? A ser assim, eram verdadeiros nobres a quem só faltava remediar o defeito de nascença e garantir-lhes a possibilidade de herdarem? "Despenso com el e legitimoo e façoo liidimo" eram as palavras com que o Rei apagava a macula, acolhia o 
ilegítimo no seio da sua família e resolvia o problema da sucessão patrimonial de um dos seus progenitores ou de ambos. Mas por muito que um legitimado pudesse ser igualado pelo Rei a um legítimo, a diferença subsistiria e a primazia deste sobre aquele seria sempre bem notória.

É pois, de um modo interrogativo - que é, afinal, o mais estimulante para o investigador - que concluímos esta breve apresentação do estudo que temos em curso sobre esta tão interessante e polifacetada actividade do governo do Rei D. Dinis.

\section{Bibliografia}

AFONSO X, EL SÁBIO - Las Siete Partidas Del Rey Don Alfonso El Sabio, Madrid: La Real Academia de la Historia, Tomo III, 1807.

ALBUQUERQUE, Martim de; NUNES, Eduardo Borges (eds.) - Ordenações del Rei Dom Duarte, Lisboa: Fundação Calouste Gulbenkian, 1988.

BARROS, Henrique da Gama, História da Administração Pública em Portugal nos séculos XII a XV, $2^{\mathrm{a}}$ ed. dirigida por Torcato de Sousa Soares, Tomo VI, Livraria Sá da Costa - Editora, Lisboa, 1949.

CID, Nuno de Salter, A Comunhão de Vida à Margem do Casamento: Entre o Facto e o Direito, Coimbra, Edições Almedina, 2005.

COSTA, António Domingues de Sousa - "As Concordatas portuguesas", Itinerarium, ano $12, \mathrm{n}^{\circ} 51$ (1966), p. 24-46.

- "D. Frei Tello, arcebispo-primaz, e as concordatas de D. Dinis", in IX Centenário da Dedicação da Sé de Braga. Congresso Internacional. Actas, II/1, Braga (1990), p. 283-316.

Livro das Leis e Posturas (prefácio de Nuno Espinosa da Silva; leitura paleográfica e transcrição de $\mathrm{M}^{\mathrm{a}}$ Teresa Campo Rodrigues), Universidade de Lisboa - Faculdade de Direito, Lisboa, 1971.

LOPES, Fernando Félix - "A propósito do conflito entre a Igreja e Portugal no tempo de D. Dinis" [1964], in F. F. LOPES, Colectânea de Estudos de História e Literatura, III, Lisboa, 1997, p. 185-194.

LOURENÇO, Maria Teresa Ferreira - As cartas de Legitimação no reinado de D. Afonso V, Lisboa, 1998 (tese de Mestrado em História Medieval, apresentada à Faculdade de Letras de Lisboa).

- "Legitimados em Torres Vedras no século XV", in Turres Veteras II: Actas de História Moderna. Torres Vedras: Câmara Municipal de Torres Vedras, 2000, pp. 53-59. 
MARREIROS, Maria Rosa, Chancelaria de D. Dinis . Livro II, Coimbra/Viseu: Universidade de Coimbra: Centro de História da Sociedade e da Cultura Palimage Editores, 2012.

MATTOSO, José - «Introdução: Legitimação e Linhagem», e-Spania [En ligne], 11 juin 2011.

MERÊA, Paulo - "Perfilhação - achega para um dicionário histórico da Língua Portuguesa", Revista Portuguesa de Filologia, vol. VII (1956), p. $118-127$.

MORENO, Humberto Baquero - Subsídios para o Estudo da Sociedade Medieval Portuguesa. Moralidade e Costumes. Dissertação de licenciatura em Ciências Histórico-Filosóficas apresentada à Faculdade de Letras da Universidade de Lisboa, 1961.

- "Subsídios para o Estudo da Legitimação em Portugal na Idade Média. D. Afonso III a D. Duarte", Revista dos Estudos Gerais Universitários de Moçambique, vol. IV, Série V, 1967, p. 209-237.

OLIVEIRA, António Resende de - Depois do Espectáculo Trovadoresco. Estrutura dos cancioneiros peninsulares e as recolhas dos séculos XIII-XIV, Coimbra: Edições Colibri, 1994.

- "Distracções e Cultura", in VENTURA, Leontina - D. Afonso III, Lisboa: Círculo de Leitores, 2006.

Ordenações del-Rei Dom Duarte (Ed. de Martim de Albuquerque e Eduardo Borges Nunes), Fundação Calouste Gulbenkian, Lisboa, 1988.

PEDRO, Conde D. - Livro de Linhagens, [1340], in Portugaliae Monumenta Historica, Nova Série. Ed. crítica por José Mattoso. Lisboa: Academia das Ciências, 1980, 2 vols.

PIZARRO, José Augusto - Linhagens Medievais Portuguesas. Genealogias e Estratégias (1279-1325), 3 vols., Porto, Centro de Estudos de Genealogia, Heráldica e História da Família, 1999.

- “A nobreza portuguesa no período dionisino. Contexto e estratégias (1279-1325)", En la España Medieval, Madrid: Universidad Complutense, n ${ }^{\circ} 22$ (1999).

- D. Dinis, Lisboa, Círculo de Leitores, 2005.

RODRIGUES, Maria Teresa Campos (ed.) - Livro das Leis e Posturas, Lisboa, CML, 1974.

ROSA, Maria de Lurdes - O morgadio em Portugal, séculos XIV-XV. Modelos e práticas de comportamento linhagístico, Lisboa, Lisboa, Ed. Estampa, 1995. SOUSA, Bernardo de Vasconcelos e-Os Pimentéis: percursos de uma linhagem da nobreza medieval portuguesa: séculos XIII-XV. Lisboa, Imprensa Nacional-Casa da Moeda, 2000. 
TEIXEIRA, Carla Maria de Sousa Amorim - Moralidade e costumes na sociedade de Além-Douro. 1433-1521 (a partir das legitimações), Porto, 1996.

_ "As legitimações no além-Douro (1433-1521)", Estudos em Homenagem ao Professor Doutor José Marques, Universidade do Porto, 2006, vol. I, p. 429-437.

TEIXEIRA, Sónia Maria de Sousa Amorim - A vida privada entre Douro e Tejo: estudo das legitimações (1433-1521), Porto, 1996.

VASCONCELOS, Carolina Michaëlis de -A Saudade Portuguesa.Divagações filológicas e Literar-Históricas em volta de Inês de Castro e do Cantar Velho, Colecção Filosofia \& Ensaios, Guimarães Editores, Lisboa, 1996.

VENTURA, Leontina - A Nobreza de Corte de Afonso III, 2 vols., Coimbra: Faculdade de Letras, 1992 (dissertação de doutoramento).

- D. Afonso III, Lisboa, Círculo de Leitores, 2006.

- e OLIVEIRA, António Resende de (eds.) - Chancelaria de D. Afonso III, Livro I. Vols. 1 e 2; Livros II e III, Coimbra: Imprensa da Universidade de Coimbra, 2006-2011.

VIEGAS, Valentino - Subsídios para o Estudo das Legitimações Joaninas: 1383-1412, Odivelas, Heuris, 1984. 